\title{
Construction of Shale Gas Well
}

\author{
Aneta Sapińska-Śliwa ${ }^{1,{ }^{*}}$, Rafat Wiśniowski ${ }^{1}$, and Krzysztof Skrzypaszek ${ }^{1}$ \\ ${ }^{1}$ AGH University of Science and Technology, Krakow, Poland, Faculty of Drilling, Oil and Gas, \\ A. Mickiewicza Av. 30, 30-059 Krakow, Poland
}

\begin{abstract}
The paper describes shale gas borehole axes trajectories (vertical, horizontal, multilateral). The methodology of trajectory design in a two- and three-dimensional space has been developed. The selection of the profile type of the trajectory axes of the directional borehole depends on the technical and technological possibilities of its implementation and the results of a comprehensive economic analysis of the availability and development of the field. The work assumes the possibility of a multivariate design of trajectories depending on the accepted (available or imposed) input data. Key words - shale gas, construction of the well, unconventional reservoirs.
\end{abstract}

\section{Introduction}

Due to an increased demand for energy and changing trends, resources not produced so far because of the lack of a suitable technology available started to be reached out for. Such resources are unconventional gas and oil reservois the production of which, on a larger scale, started at the end of 20th century. Presently, the largest producer of gas from unconventional reservois is the United States. In 2004, the production of shale gas in the US accounted for $5 \%$ of the amount of gas being produced and in 2016 it was as high as $60 \%$. Gas production had been preceded by many years of research on a new technology, which would enable achievement of economically justified gas flows. The key to success became the application of horizontal drilling technology and hydraulic fracturing.

Opening a shale gas reservoir consists in drilling of a gas formation with a network of directional boreholes with end horizontal sections, with outlets located in close proximity, i.e. group wells. Grouping of well outlets at small intervals (a multiwell pad) has a number of advantages, yet, it requires very precise well design and performance. In this case, vertical sections are located very close to one another, which, together with imprecision of measurement instruments, may result in well collision. In the event that wells are operational, such collision may lead to eruption, and thus, to direct threat to life of the drilling rig staff. Well performance is preceded by a designing process, which has to take into account all factors affecting the precision of calculations and measurements. Well design may be supported by such computer programs as Compass, Petrel, WellArchitect or 3DPathDesigner, created at the Drilling, Oil and Gas Faculty. All those programs have tools calculating the course of borehole trajectory and enable estimation of the required separation between boreholes [1, 2].

\footnotetext{
* Corresponding author: ans@agh.edu.pl
} 


\section{Conventional and unconventional hydrocarbon fields, including hydraulic fracturing}

Over the last dozen years, continuous growth in the number of directional boreholes in relation to the total number of drilled boreholes has been observed. This phenomenon relates to the development of technologies allowing exploitation of unconventional raw material reservoirs, which are closely related to directional boreholes. Conventional energy sources are located at a small depth, whereas permeability of rocks creating them is high. Good conditions enable effective reservoir production by means of vertical wells, which translates into low investment costs. Unconventional reservoirs (shale gas \& liquid, tight oil \& gas) are located much more deeply and, additionally, rock-mass is characterised by very low permeability. Opening of an unconventional reservoir by means of standard methods, characterised by low gas flow, is most frequently uneconomic. A better solution is directional wells with end straight-lined sections running along the productive level. Such location of a borehole in a reservoir layer enables increasing of the contact surface with the reservoir rock, which translates into a higher stream of volume $[6,7]$.

Directional boreholes are also used for opening gas storage facilities in salt caverns, coalbed methane, making wells near faults, bypassing obstacles in vertical boreholes, or liquidating eruptions.

Hydraulic fracturing is an example of a procedure increasing gas inflow to a borehole. This technology was introduced in 1948 by J.B. Clark of Standolind Oil and Gas Co. The first intensification procedures were carried out in 1960's. The technology of fracturing poorly permeable shales was developed in 1980's by George T. Mitchel. In 2000, Devon Energy Co. became the owner of the said company and combined the fracturing technology with the horizontal drilling technology. The application of this intensification procedure enables to obtain economically profitable gas flow from shale formations to the well - this method has become the reason for abrupt production growth from unconventional reservoirs.

Hydraulic fracturing consists in fluid injection under pressure, exceeding fracturing pressure of the centre, which leads to its crashing. Fluid is injected through casing perforated in indicated places of the horizontal section (fracturing stations). Fractures occurring in this way are maintained in an open state by a proppant, being quartz sand or any other material with high compressive strength. Proppant permeates inside fractures and makes their closure impossible after pressure release. Fractures propagate along the largest compressive stresses. As mentioned above, hydraulic fracturing can be performed in vertical wells; in such case, the growth of the contact surface between the well and the reservoir is not so large (Fig. 1).

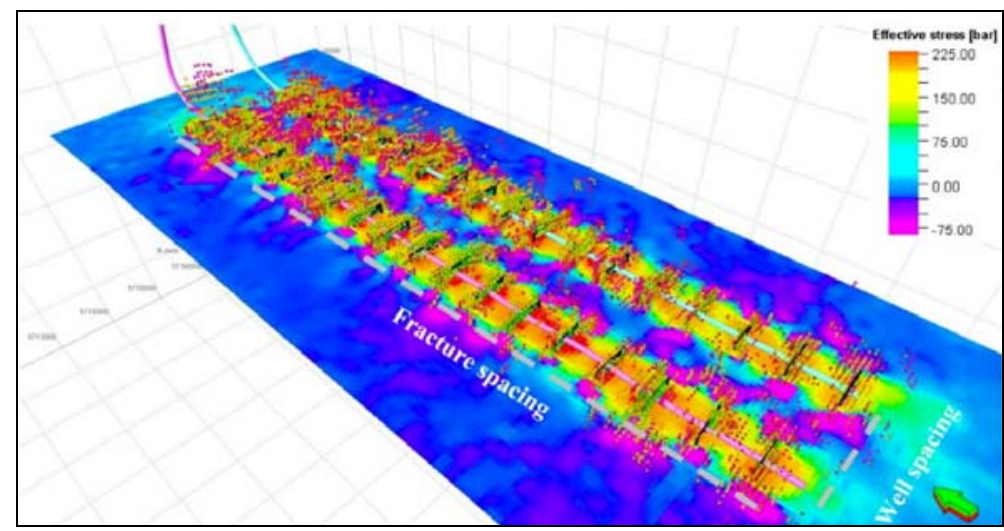

Fig. 1. Distribution of stresses and range of fracture propagation during hydraulic fracturing in horizontal sections of a drilling borehole [5] 


\section{Way of distributing directional boreholes in case of unconventional reservoirs}

In case of opening unconventional reservoirs (e.g. shale gas), a distance between wells cannot be long. It is due to a small impact range of the well in layers of poorly permeable shales. The impact range after hydraulic fracturing is, on average, $150-250 \mathrm{~m}$ in a horizontal direction. For the needs of this study, the way of opening a piece of the reservoir, $3.5 \mathrm{~km}$ per 1.5 $\mathrm{km}$ in size, has been analysed. When performing a vertical well, together with an intensification procedure, one can cover the surface corresponding to the area of a circle with the radius equal to the scope of fracturing (ca. $250 \mathrm{~m}$ ), assuming that the scope of fractures will be slightly larger and will cover the area of a square with the side equal to a double radius of fracturing, 21 vertical well will fall on the area under analysis (Fig. 2).

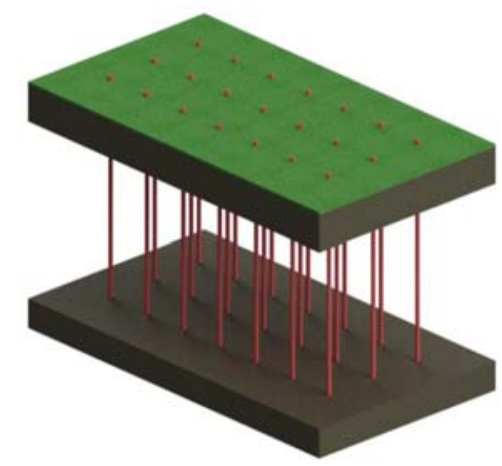

Fig. 2. Number of vertical boreholes covering a given area

When analysing the above arrangement, one may notice that the number of wells is large compared to the covered surface, and the investment project can be not economically viable. In order to reduce the number of well, one can make a directional well with a horizontal section in a gas layer. Assuming that the deviation from the vertical direction is about $900 \mathrm{~m}$ (the sum of a curvilinear section projection on the horizontal plane and the length of the horizontal section), whereas the range of fracturing will be the same as previously, 12 directional boreholes will be necessary to open a piece of the reservoir. The situation has been presented in Figure 3.

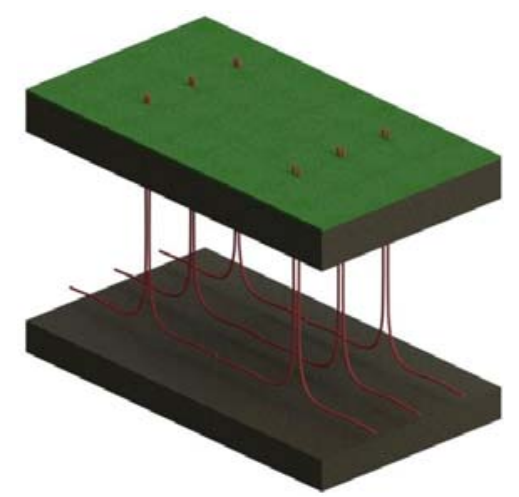

Fig. 3. Directional boreholes in a $2 \mathrm{D}$ space

The application of the directional drilling technology (2D) has enabled reduction of the number of boreholes (from 21 down to 12) and the working area on the surface. The available 
technology allows drilling of horizontal sections even up to $10 \mathrm{~km}$ (Extended Reach Wells), whereas in the case under analysis, 6 wells can be applied with a deviation from the vertical direction by ca. $1750 \mathrm{~m}$ or even longer sections, which will enable to reduce their number even more. 2D directional boreholes have enabled to reduce significantly the number of wells, however, their distribution on the surface is still not designed optimally. Drilling rigs sites are located at long distances from one another and there are plenty of them; in such situation it is necessary to transport heavy equipment. Figure 4 presents the diagram of opening a piece of the reservoir by means of 3D directional boreholes. Owing to this technology, well outlets are more grouped, which decreases the required area and the number of equipment relocations.

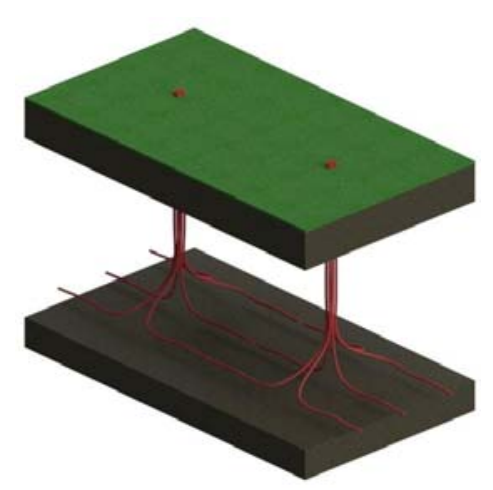

Fig. 4. Directional boreholes in a 3D space - Well Pad Drilling

Advantages of group well distribution are the following [8]:

- reduction of the required area on the surface for the performance of drilling works, a smaller amount of working areas, a lower negative impact upon the natural environment, a possibility to open reservoirs under inaccessible sites and protected areas,

- no need to dismantle and relocate heavy equipment many times to each well, modern drilling rigs have a stepper mechanism enabling moving among outlets of group wells, reducing road traffic and the number of necessary access roads,

- reduction of drilling time per well (by $50 \%$ or more) due to equipment concentration in one place and no need to dismantle the equipment each time,

- one water tank for hydraulic fracturing for the whole group of wells (even up to 12), a possibility to use the same water and chemical agents many times,

- after making of the first well up to date results of geological studies are obtained, which enable drilling optimisation and cementing subsequent wells, as geology will be similar, due to a short distance between wells,

- concentration of extraction instruments in one place,

- possibility to reduce costs when drilling a high number of wells.

Disadvantages of group well distribution [8]:

- higher cost of a single well, in particular, for companies not having any experience in performing wells,

- longer working time in one place and a larger area is required in one place,

- a well is more difficult to make and it requires a higher number of pipes and grout,

- special equipment and software is required for designing and drilling wells with variable azimuth, together with a module estimating the risk of collision.

The development of directional drilling technology enables to perform more and more complex boreholes. Owing to continuous development of this drilling sector, the price of 
directional drilling services is declining, through which it is possible to perform the abovepresented diagrams of drilling unconventional reservoirs.

Summing up the advantages and disadvantages and taking into account trends on markets of the largest producers of natural gas from unconventional reservoirs, one can state that making shale gas and tight gas available is economically viable, whereas group location of well outlets enables cost reduction and improvement of environmental aspects. Group location of outlets, due to the proximity of neighbouring wells in vertical sections and the beginning of curving, requires using advanced techniques of designing drilling borehole trajectories, highly precise measurement devices, as well as tools allowing to analyse measurement data and to estimate risks of collision.

\section{Computer aided design of directional wells trajectories in case of unconventional reservoirs}

For the needs of supporting the designing process of directional boreholes trajectories at the Faculty of Drilling, Oil and Gas at AGH University of Science and Technology, within the frameworks of the OPTIDRILLTEC program, the authors of the article created open software utilising state-of-the-art IT technologies. The application is irrespective of the operating systems being used or the hardware platform; it was developed using php and java languages and it can work in new internet browsers. Such a solution has a number of advantages, for instance, a possibility to use the program on desktops, tablets, smartphones; scalability of the number of users; access to the collected complete knowledge base; data security on the server side (Fig. 5).

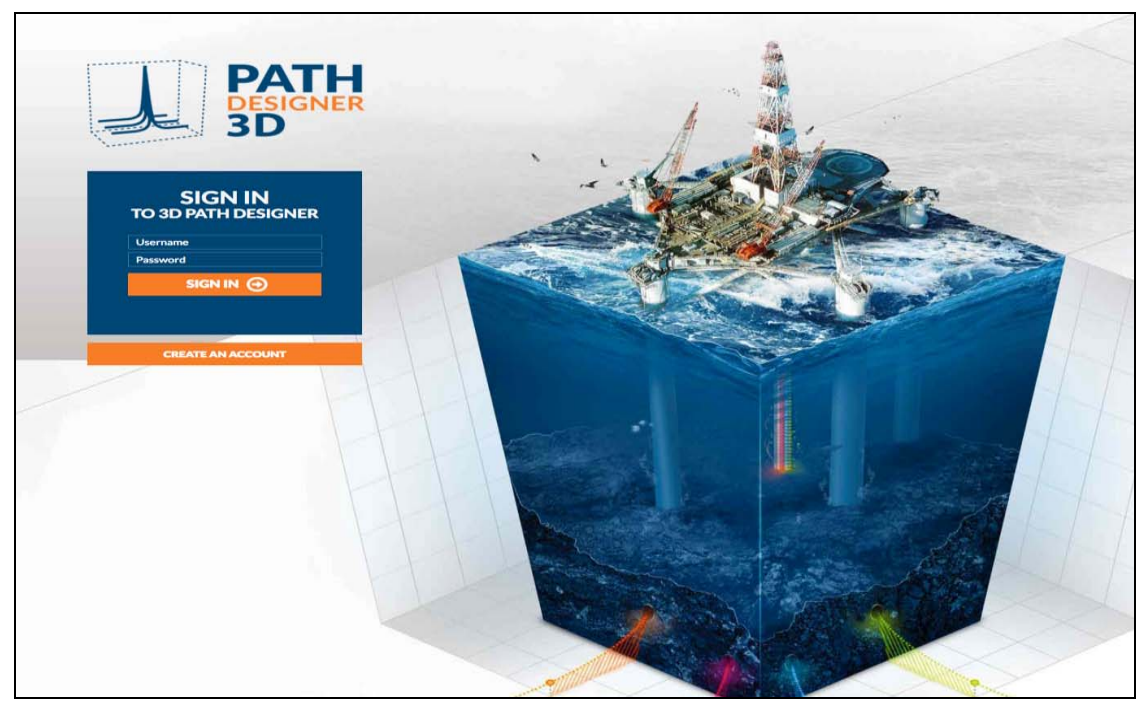

Fig. 5. Login window of the 3DPathDesigner application

The 3DPathDesigner application uses algorithms to calculate trajectories created within the frameworks of research work by the authors of this article [3, 4]. Below, Figure 6 present an interface for designing 2D-type trajectories (with a constant azimuth); it enables very comfortable preparation of even very complex trajectory shapes, taking into account most of designer's expectations. 
a)

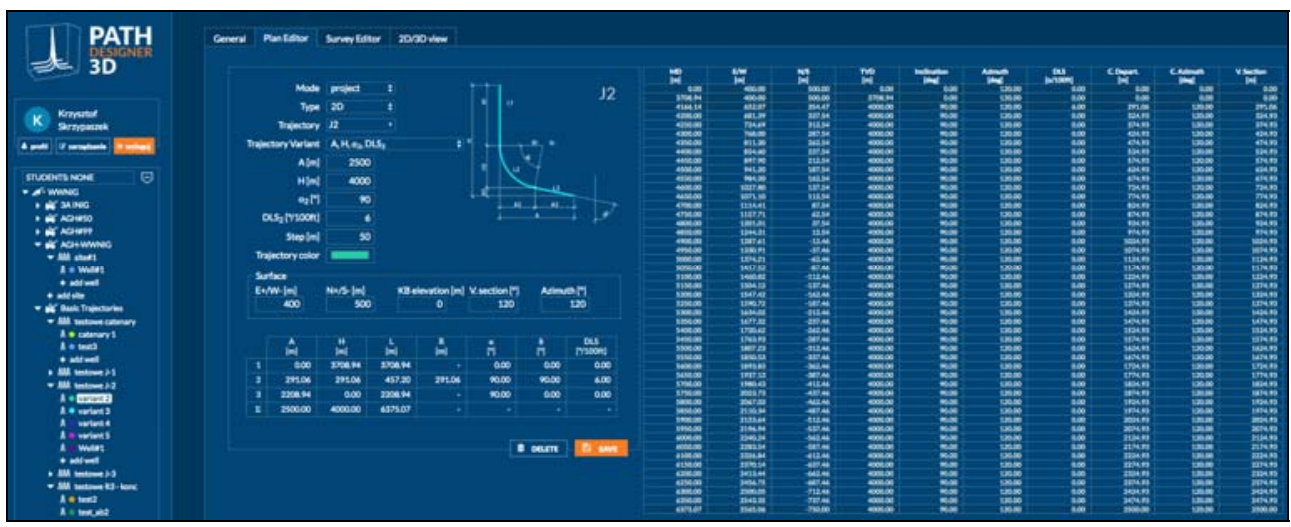

b)

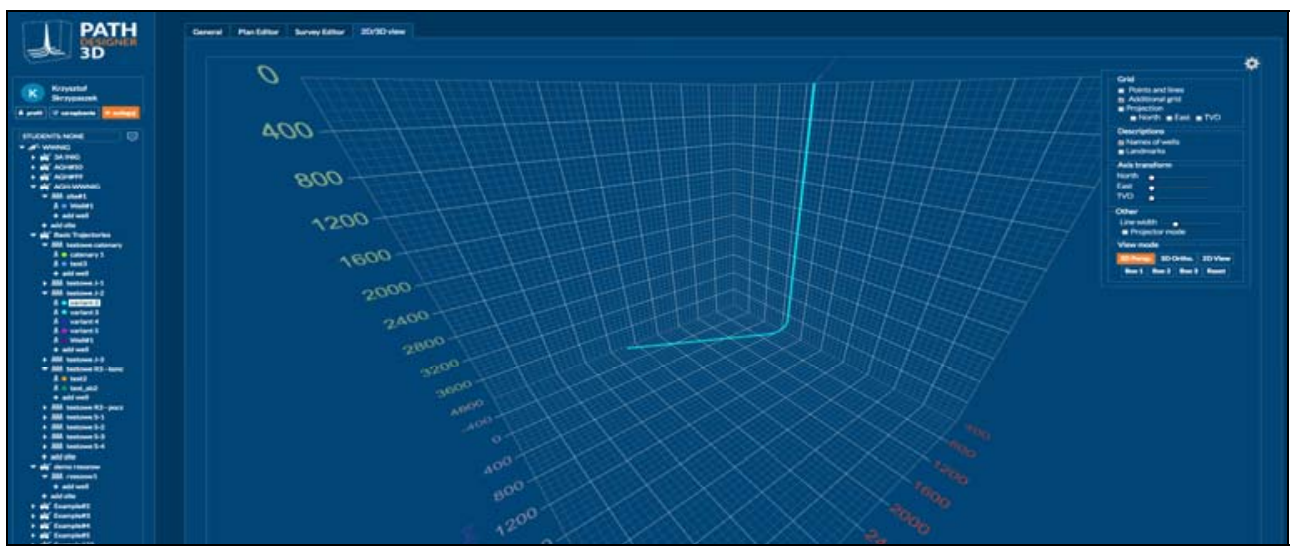

Fig. 6. Window of designing a 2D trajectory in the 3DPathDesigner application

3DPathDesigner program makes it possible to prepare complex designs of this kind. Figure 7 presents user tools within the scope of trajectory designing in a 3D space (with variable azimuth), whereas Figures 8 and 9 show application possibilities when designing ERW-type well networks and multilateral wells, respectively.

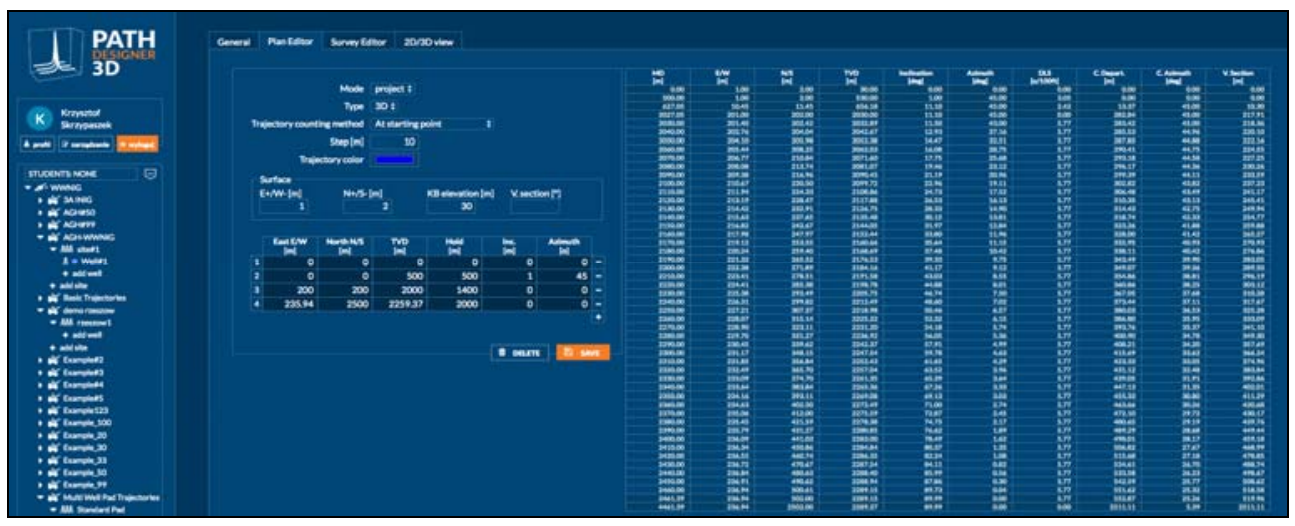

Fig. 7. Window of designing a 3D trajectory in the 3DPathDesigner application 


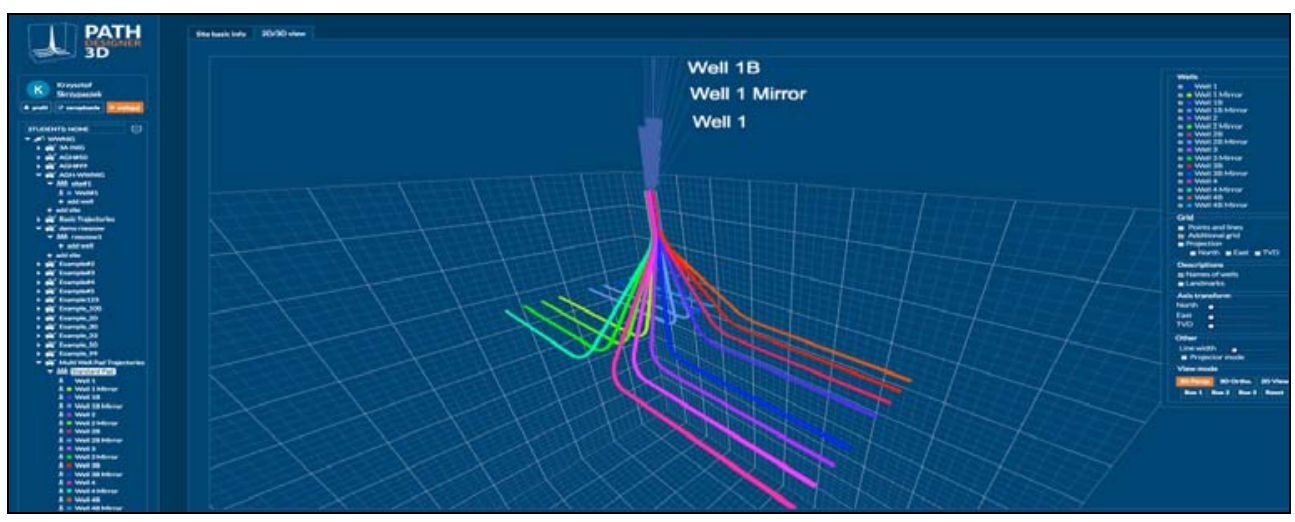

Fig. 8. Window of designing trajectories of a network of fracturing wells with a long horizontal section (ERW) in the 3DPathDesigner application

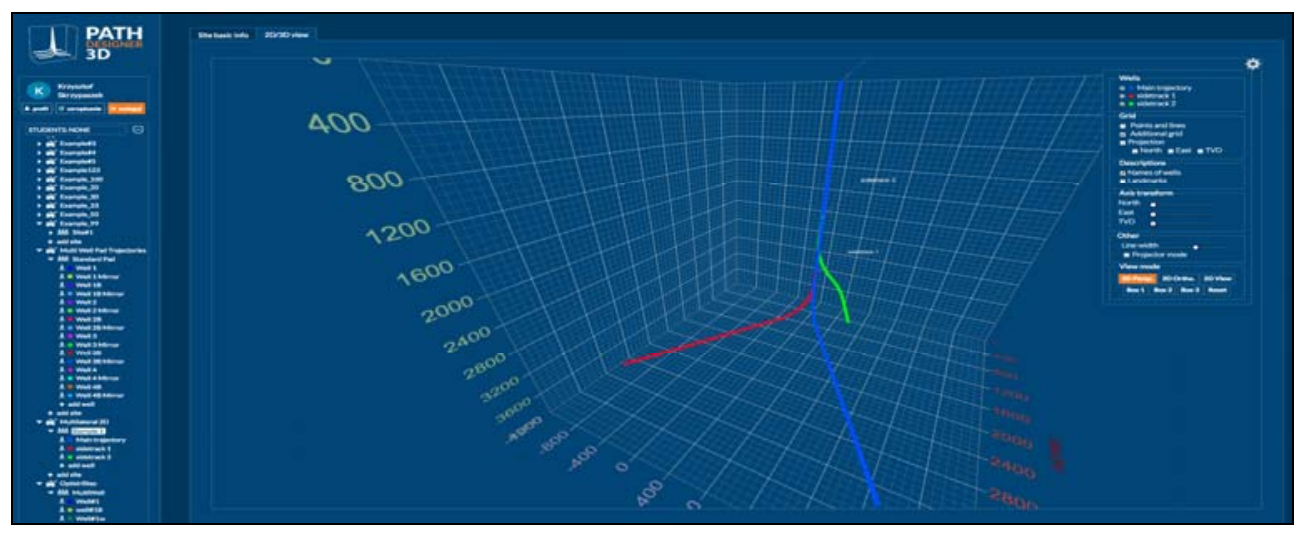

Fig. 9. Window of designing trajectories of a network of multilateral wells in the 3DPathDesigner application

Directional boreholes in a 3D space require special structures. It relates, first of all, to the intensity of such boreholes curving.

\section{Conclusions}

1. Grouping of borehole outlets at a short distance, i.e. on a pad, allows to reduce the surface of a necessary working area, it has a lower impact upon the natural environment than single 2D boreholes; it eliminates the necessity to relocate equipment frequently; it reduces total costs of making wells;

2. Computer programs, such as 3DPathDesigner, enable fast and simple designing of a trajectory axes of the directional borehole and the analysis of anti-collision by means of charts of separation index and the centre-to-centre distance;

3. Kind of measurement devices applied has an impact upon optimum distribution of outlets of group directional boreholes.

4. The application of grouped wells requires special drilling techniques. They enable very precise maintenance of the assumed well axis trajectory, up-to-date control and verification.

5. Wells drilled in a single pad have special structures enabling selective gas exploitation, making available a bundle of operational heads concentrated on the surface. 
6. Rolling drilling devices enable relocation on the site without dismantling and installation again. It limits the time spent on performing a bundle of wells. Time reduction in the drilling industry usually leads to savings. Although a single well can be more expensive, savings due to no need to dismantle and installation of drilling equipment again lead to lower costs in total for all wells.

\section{Acknowledgements}

The paper was created within statute studies at the Faculty of Drilling, Oil and Gas at AGH University of Science and Technology in Krakow, Poland. Grant no. 11.11.190.555.

\section{References}

1. A. Jamieson (ed.), Introduction to wellbore positioning, University of the Highlands and Islands, (2012), (access on internet: 21.08.2017),

http://www.uhi.ac.uk/en/research-enterprise/energy/wellbore-positioningdownload

2. Why Multiple Horizontal Wells from centralized well pads should be used for the Marcellus Shale, (access on internet: 21.08.2017):

http://wvsoro.org/multiple-horizontal-wells-centralized-well-pads

3. R. Wiśniowski: Metodyka określania przebiegu trajektorii otworu kierunkowego, Materiały wykładowe, (no published)

4. R. Wiśniowski: Wybrane aspekty projektowania konstrukcji otworów kierunkowych z wykorzystaniem technik numerycznych, AGH University Press, Kraków, (2002)

5. J. Schofield, A. Rodriguez-Herrera, X. Garcia-Teijeiro, Optimization of Well Pad \& Completion Design for Hydraulic Fracture Stimulation in Unconventional Reservoirs, SPE-174332-MS, EUROPEC, Madrid, Spain (2015)

6. Multi-Well Pad Operations for Shale Gas Development, (access on internet: 21.08.2017) http://gekengineering.com/Downloads/Free_Downloads/MultiWell_Pad_Operations_For_ Shale_Gas_Developmen.pdf

7. S. Rychlicki (ed.), Poradnik Górnika Naftowego, 2, Press SITPNiG (2015)

8. M. Ostadhassan, S. Zamiran, H. Jabbari, A. Osouli, B. Bubach, B. Oster, Stability Analysis of Multilateral High Density Pad Wells In the Three Forks Formation, SPE174040-MS, SPE Western Regional Meeting, Garden Grove, California, USA, (2015) 